\title{
Imaginarios y ficciones de la muerte en la posmodernidad
}

Imaginaries and Fictions of Death in Postmodernity

Imaginaires et fictions de la mort dans la postmodernité

\section{Aitana Martos García y Alberto E. Martos García}

\section{OpenEdition}

\section{Journals}

Edición electrónica

URL: http://journals.openedition.org/rccs/6941

DOI: $10.4000 /$ rccs.6941

ISSN: 2182-7435

Editor

Centro de Estudos Sociais da Universidade de Coimbra

Edición impresa

Fecha de publicación: 1 mayo 2018

Paginación: 5-28

ISSN: 0254-1106

\section{Referencia electrónica}

Aitana Martos García y Alberto E. Martos García, « Imaginarios y ficciones de la muerte en la posmodernidad », Revista Crítica de Ciências Sociais [En línea], 115 | 2018, Puesto en línea el 15 mayo 2018, consultado el 30 abril 2019. URL : http://journals.openedition.org/rccs/6941 ; DOI : 10.4000/ rccs. 6941 


\section{AITANA MARTOS GARCÍA, ALBERTO E. MARTOS GARCÍA}

\section{Imaginarios y ficciones de la muerte en la posmodernidad}

Este ensayo analiza el intercambio y labilidad entre las representaciones ficcionales de la muerte en el contexto de una cultura posmoderna, donde la inteligencia artificial y otras corrientes culturales y científicas han remodelado nociones básicas como las ideas de alma o de muerte. El poshumanismo constituye un nuevo horizonte al enfatizar las nuevas relaciones entre personas, animales y máquinas, y viene precedido por las visiones del transhumanismo, que implica una inversión de las cosmovisiones tradicionales acerca del cuerpo y de la muerte. La hipótesis del presente trabajo es que los imaginarios tecnocientíficos, particularmente a través de las ficciones futuristas, han remodelado la idea de muerte, que deja de ser un fatum para convertirse en una anomalía o mecanismo que se puede corregir con la ciencia. Podemos concluir que muchas de las utopías recreadas en los imaginarios son tecnotopías propias de la posmodernidad y, en ese aspecto, cobran sentido tales representaciones posmodernas de la muerte como expresión de un milenarismo y de una catarsis colectiva que reconcilian la dimensión racional e irracional humana.

Palabras clave: inteligencia artificial; imaginarios de la muerte; poshumanismo; posmodernidad.

Palavras-chave: inteligência artificial; imaginário da morte; pós-humanismo; pós-modernidade.

\section{Algunas perspectivas teóricas}

En relación con los pilares aristotélicos del discurso ethos, pathos y logos (Braet, 1992), es notable que las reflexiones del pensamiento transhumanista (Bostrom, 2011) tiendan a eliminar el pathos, es decir, las pasiones en torno a la idea misma y la vivencia de la muerte o lo que Unamuno llamó "el sentimiento trágico de la vida" (1983 [1912]).

Es verdad que esta huida del trascendentalismo, por así decir, se apoya no solo en los nuevos signos de la (pos)modernidad, en su énfasis por lo cotidiano o la instantaneidad, sino que tiene otras raíces estéticas y filosóficas 
como la repulsión o aversión de las vanguardias a incluir la muerte en su horizonte de preocupaciones; así, el genial Ramón Gómez de la Serna es el paradigma del artista que se niega a representarla en su universo artístico si no es como objeto de burla (muñecas de cera; Begoña, 1980); o bien, en las exposiciones artísticas actuales, a modo de "reciclado" o "provocación" (exposición de cadáveres polimerizados -Bodies Revealed de la empresa Premier Exhibitions-, generados a partir de la técnica de plastinación del médico alemán Gunther von Hagens).

Estudios efectuados a partir de la bioética, la neurociencia o el materialismo eliminativo (Echarte-Alonso, 2012) soslayan las posiciones más tradicionales, por ejemplo el debate sobre la conciencia, para poner énfasis en los aspectos concretos que más tienen que ver con el bienestar, como la psicofarmacología; es decir, ponen el enfoque en el cuerpo y sus demandas, en una búsqueda incesante de la perfección (Cruz, 2009) que les lleva a un negacionismo utópico de la muerte. Hay que enseñar a los niños que la muerte no es un fatum, un destino inexorable, sino un "error" (Death is Wrong; Stolyarov, 2013) o anomalía que la ciencia y la tecnología corregirán.

Desde una óptica puramente médica, es lógico que la neurocosmética, los tratamientos para la prolongación de la vida, incluso el estilo de los servicios funerarios (Pintos, 2006), impongan una visión light donde lo ceremonial, la trascendencia o el ámbito público - propio de los velatorios tradicionales- se trivialicen hacia una secuencia o script donde "la muerte es despojada de cualquier búsqueda de sentido del hecho" (ibidem: 575), tal como ocurre en los tanatorios actuales. Así, el maquillaje del cadáver (tanatopraxia) constituye un ejemplo emblemático de esta actitud elusiva hacia la muerte (Echarte, 2012).

\section{El shock del futuro, la era tecnodigital y la reconfiguración de la muerte}

En el mito clásico la muerte es el horizonte natural de la aventura, el riesgo siempre presente y, por lo tanto, forma parte de la experiencia "iniciática" de la aventura que no tiene sentido alguno al margen de la misma. De hecho, sabemos por Propp (1985 [1928]) que las pruebas iniciáticas eran una simulación de la muerte.

Los nuevos horizontes que integran las ciencias, han hecho confluir numerosas disciplinas para esbozar un hombre futuro nuevo y han provocado lo que Toffler (1970) llama el shock del futuro. Esto es lo que se ha dado en llamar seres posbiológicos, es decir, aquellos que como el cíborg rebasan la dimensión biológica convencional para explorar otras alternativas (Fukuyama, 2002). Pero no solo la robótica o la biología están "imaginando" este hombre futuro. Otras muchas disciplinas no puramente tecnológicas, 
como las neurociencias o la educación, están prefigurando nuevos escenarios donde, como dice Sloterdijk (2003), las personas tendrán que aprender a convivir de manera diferente no ya entre sí, sino con los animales y las máquinas.

Respecto a esto, según el propio Isaac Asimov (1986), el sentido último de la ciencia ficción es anticipar los cambios sociales; en este aspecto, a veces se ha infravalorado el papel de las ficciones e imaginarios para adelantar y visibilizar estos cambios inminentes. También Raulerson (2013) abunda en esta misma dirección. En 1987, RoboCop parecía una pura fantasía belicista, pero hoy ficciones como Transcendence o Surrogates/Los sustitutos $\mathrm{y}$ otras ponen en primer plano la centralidad de esta nueva humanidad, que va a poder derrotar a la muerte a largo plazo o, al menos, prolongar la vida gracias a una simbiosis de avances médicos y biológicos, robótica y cambios en la organización social.

La contraposición de Lévi-Strauss entre naturaleza y cultura (1987) que vertebraba la reflexión antropológica clásica, ahora se ve rebasada por otras dicotomías como la diferencia entre lo biológico -fungible y sujeto a caducidad- y lo artificial o implantado, que equivale a lo inmortal. También nos enfrentamos a los nuevos retos surgidos de la inteligencia artificial como ciencia y tecnología a la vez, la cual irrumpe en la vida cotidiana con artefactos que ya no son simples tostadoras, sino "entes capaces de pensar", incluso máquinas autorreplicantes (García Díaz et al., 2004) que ponen en duda, por eso mismo, las leyes robóticas pensadas por Asimov e incluso el mismo orden social, tal como se visualiza en películas distópicas como I, Robot/Yo, Robot (2004), Surrogates (2009), etc.

Así surgen como ejemplos de inmortalidad los robots y los cíborgs (Clynes, 1960), pero esta nueva realidad supone una recategorización de la muerte; al acercar la inmortalidad a la noción no de organismo vivo sino de máquina, mucho más resistente y perenne, se pone el énfasis en las tecnologías conducentes a estos cambios y en las repercusiones de las mismas, en especial el impacto social y las consecuencias éticas, en la medida en que más bien estarán al alcance de unas élites y probablemente generarán exclusión y conflictos (Gray, 2000).

\section{De máquinas, autómatas y cíborgs}

Para el imaginario popular el autómata es sinónimo de algo siniestro, por eso se asocia con la muerte y, secundariamente, con el zombi. El estereotipo es conocido: las máquinas no tienen alma (Fernández Castrillo, 2008), luego no tienen vida. Pero esto es algo que ya cuestiona la inteligencia artificial, si entendemos por tener vida "la capacidad de pensar y aprender con autonomía” o el que ya se puedan fabricar máquinas autorreplicantes. 
Es más, el materialismo eliminativo, al dejar fuera las cuestiones relativas a la conciencia, es capaz de reenfocar esta problemática al pretender que nociones psicológicas como las creencias, los deseos o las intenciones no serían más que epifenómenos de la función cerebral que el progreso de las neurociencias acabará por dejar obsoletos.

Para un robot la muerte no es más que un stand-by mientras se reprograma o se "migra" su UCP a otro "envoltorio"; por lo tanto, morir no sería ese largo discurso unamuniano, sino simplemente "dejar de funcionar".

Ha sido frecuente el enfoque reduccionista de la máquina, concebida como un utensilio al servicio del capitalismo y de los flujos económicos y de explotación de bienes, en general; por lo tanto, el mundo de las máquinas se percibía como algo exclusivo de los técnicos, igual que el urbanismo se reservaba a los arquitectos, en un enfoque bipolar ciencias/letras o técnica/humanismo (Martos, 2010) que sustraía al debate o a la opinión de los ciudadanos las cuestiones más candentes. Este mismo reduccionismo es el que los imaginarios, en el folclore y la literatura, han aplicado a la visión de lo que hoy conocemos como "híbrido", descrito como "lo maravilloso", es decir, aquello que concierne a la representación de dioses, monstruos u otros seres mitológicos.

Por lo tanto, la reflexión al hilo de las teorías culturales debe llevarnos a repensar, a recategorizar estas cuestiones. Por ejemplo, como bien explican Deleuze y Guattari (1972), cabe distinguir entre máquinas sociales y máquinas deseantes; de igual manera, hay máquinas materiales y máquinas inmateriales, como el software.

Bajo esta nueva visión, es normal percibir que "máquina, hombre y naturaleza" forman un todo (Sloterdijk, 2003) y que figuras como el cíborg, al relativizar el concepto de cuerpo o la diferencia entre lo orgánico y lo tecnológico, nos remiten nuevamente al concepto de máquina deseante o, dicho de otro modo, al concepto de identidad como ilusión, a la necesidad de un nuevo humanismo (o poshumanismo, según Solterdijk) que incorpore $\mathrm{y}$, al procesar estos valores y conflictos emergentes, reconceptualice los términos del problema. De ahí este diagnóstico algo pesimista, que casi formula en sentido abstracto ficciones como The Matrix.

\section{Estudio de casos. Las representaciones ficcionales de la muerte en la literatura y el cine de las últimas décadas}

En el caso de los imaginarios, tanto en el folclore como en la literatura, los videojuegos o los transmedia, es decir, en el campo de la "subcreación" según el concepto de Tolkien (1994), bajo el disfraz distorsionado de monstruos y peripecias truculentos anidan verdades ocultas que los sociólogos, por ejemplo, analizan a propósito de las distopías. 
Asimov (1986) vislumbró todo esto cuando advertía que el sentido de la ciencia ficción no era, en realidad, hablar de marcianos o naves futuristas dentro de ese continuo "banquete narrativo" que proporcionan muchas superproducciones, sino que a través de la fabulación se expusieran los cambios que afectarán a la humanidad, así como el impacto que éstos generarían.

De hecho, el folclore, con el cuento judío de El golem, o la literatura, con la figura del monstruo de Frankenstein, de Mary Shelley (2009 [1818]), han prefigurado las representaciones actuales del robot. Los primeros autómatas ya tienen precedentes en Las metamorfosis de Ovidio en el año 8 después de Cristo. Efectivamente, Rowen (1992) ya habla de la composición del personaje de Shelley como un posgólem o un prerrobot. Sobre la vida artificial convertida en autómata existe una tradición en la literatura y el mito, como vemos en Ovidio y otros clásicos (Pulido Tirado, 2012). Es cierto que una visión sociofilosófica de Frankenstein (Latour, 2011) ha alertado de los riesgos; por ejemplo, acerca de cómo el afán humano de emancipación de los principios morales y divinos clásicos puede llevar a ciertos conflictos y pesadillas (Martos y Martos, 2013).

Los superhéroes y los supervillanos, los monstruos de todo tipo, desde Godzilla a los Gremlins (Vronsky, 2004) y los personajes corales (The Avengers/Los Vengadores, 2012-2018), conforman un personaje colectivo símbolo de la (pos)modernidad que se podría resumir en una frase: la expresión de la "alteridad" derivada hacia lo grotesco, hiperbólico o neobarroco.

Hablamos de "personaje-enjambre" no solo porque a menudo estos héroes o villanos se coaliguen; la red misma se puede considerar una mega-máquina ensamblada en otras máquinas e incluso la multitud deviene "maquínica", como escriben Hardt y Negri en Imperio:

La multitud no usa sólo las máquinas para producir, sino ella misma deviene, contemporáneamente, cada vez más maquínica. Del mismo modo, los medios de producción están cada vez más integrados en las mentes y en los cuerpos de la multitud. En tal contexto, reapropiación significa libre acceso y control del conocimiento, de la información, de la comunicación y de los afectos, en cuanto medios primarios de la producción biopolítica. El simple hecho de que estas máquinas productivas hayan sido integradas en la multitud no significa que esta última esté en condiciones de controlarlas; al contrario, todo esto vuelve a la alienación mucho más odiosa y viciada. El derecho a la reapropiación es el derecho de la multitud al autocontrol y a una autónoma autoproducción. (Hardt y Negri, 2000: 25)

Las tesis de Hard y Negri (2000) son muy sugerentes porque inciden en los aspectos más novedosos del discurso social, visto a la luz de una 
reflexión filosófica más amplia, pero también en ese otro trasluz de los rasgos de la (pos)modernidad que se van imponiendo, en la medida en que se está creando una especie de "intelecto general" (una inteligencia social, colectiva, creada por los conocimientos y técnicas acumuladas) que se nutre de un imaginario híbrido (que va desde la Biblia o el mundo clásico a la historia euroamericana), que es precisamente el que está fabulando sobre estas identidades híbridas humanos-máquinas-animales.

El carácter profético y milenarista de algunas de las teorías de Hard y Negri se acompasa bien con el imaginario social que está calando en esas masas que buscan emancipación y que podría extenderse, apurando más la utopía, al concepto de robot o cíborg. Así, el contexto de $V$ for Vendetta (2006), de Alan Moore y David Lloyd, subraya, por su propio protagonista enmascarado, la alteridad que desafía al "orden imperial"; su proyecto de volar el parlamento, con la multitud que acude disfrazada igualmente de $\mathrm{V}$, da fe del mismo afán colectivo de emancipación.

Ciertamente, los zombis constituyen un ejemplo paradigmático de estos "personajes-enjambre"; es la representación de la muerte colectiva por antonomasia y de una de las peores fobias de los vivos -ser devorados- que ya formaba parte de los cuentos infantiles sobre dragones y tragaldabas (Martos, 2013), creando unos imaginarios del devoramiento que siguen vigentes en estos contextos de infantilización o juvenilización de los adultos, propios de la posmodernidad (Lyon, 1997; Fernández Blanco, 2004), que generan precisamente niños que son adultos prematuros y adultos que son niños eternos; es decir, que tienen el llamado síndrome de Peter Pan.

De manera más que coincidente, la moraleja de I, Robot, de Isaac Asimov (1950), es que la emancipación del robot -usado como neoesclavo por lo que Hard y Negri llaman el "imperio" antes aludido- es un imperativo moral. Aunque los tráileres de ambas películas subrayan los aspectos más efectistas, tanto la escena final de la película $V$ for Vendetta (2005) -la voladura del parlamento con la anuencia de la multitud que se congrega vestida de V-como la escena de I, Robot-los robots son liberados de los contenedores y guiados por su líder ante un horizonte incierto- son signos suficientes de este pensamiento liberador. $\mathrm{Y}$, en algún caso, anarquista, pues tiene como pretexto a las máquinas pero no da paso a una visión puramente catastrofista de las mismas, tal como sucede, por ejemplo, en la saga o franquicia The Terminator (1984-2015).

En cualquier caso, si consideramos a los espectadores de estas películas, cabe decir que "esta infantilización del adulto trae como consecuencia la ‘adultización’ del niño” (Fernández Blanco, 2004) y explica el éxito mediático de las historias de robots desde Star Wars/La guerra de las galaxias (1977). 
Lo cierto es que los temas transhumanistas aparecen por todas partes en las ficciones literarias y audiovisuales, representando a través de muchas de estas obras todos los matices de la especulación sobre la muerte, desde la visión más aséptica que aparece en 2001: A Space Odyssey/2001: Una odisea del espacio (1968), de Arthur C. Clarke, hasta las pesadillas más distópicas que jalonan los hitos del género que pasan, a menudo, por la anticipación de un futuro terrible donde las guerras, el hambre o la extenuación de los recursos y de la propia especie humana provocan cuadros desoladores, desde el ya lejano Brave New World (Un mundo feliz en español) de Huxley, de 1932.

Es lógico que el ciberpunk, desde W. Gibson a la actualidad, incluyendo el llamado posciberpunk (Person, 1998), en realidad constituya un reciclado posmoderno de elementos narrativos anteriores. En cierto modo, los personajes del ciberpunk clásico son nuevas versiones de los antihéroes anteriores que combinan temas como la invasión de las TIC, la computarización de la vida cotidiana y las modificaciones del cuerpo por vía de la bioingeniería, soslayando el debate ético o social que todas estas cuestiones podrían suscitar (Carnelos y Cava, 2009).

El paroxismo de estos elementos que distinguimos en obras de gran impacto mediático (como The Matrix, 1999; RoboCop, 1987; Prometheus, 2012, y otras muchas creaciones de otros géneros como series, videojuegos, animes, etc.) no ha dejado de popularizar entornos transhumanistas, tal como ocurre en el manga Ghost in the Shell (Shirow, 1996) desde 1989 hasta la actualidad, donde ya se aprecia que la línea entre los seres vivos y las emulaciones es borrosa, y donde asistimos a una reelaboración del concepto de alma bajo la noción cibernética de ghost. Un mundo de acciones truculentas cuyo sentido se hace opaco -salvo para la mente del héroe-y donde la dimensión del pathos ahoga a las otras, el logos y el ethos, donde el pánico inunda el escenario en busca de una posible catarsis iluminadora y redentora. La ludificación de todo este escenario narrativo, con modelos en el videojuego y en los recursos digitales (por ejemplo, un videoclip), genera un alto impacto sensorial y emocional bajo el que subyace el conflicto de fondo que se expresa en el propio título del manga Ghost in the Shell, alma dentro de una carcasa o armazón, que es este cuerpo biónico con sus prótesis y programas incorporados. En este caso, la inteligencia artificial no actúa como una simple raza de máquinas que buscan eliminar al ser humano (The Terminator, 1984), sino de una forma más sutil y con un horizonte más amplio.

\section{Los monstruos y espantos como la muerte expandida}

El monstruo se parece a la máquina precisamente por simbolizar lo no humano, es decir, lo infrahumano o poshumano, según los casos, pero ambos 
parecen obedecer al mismo principio. El monstruo compone, suelda, anuda partes de diferente naturaleza y origen hasta conformar la figura final de un organismo complejo. Así, dibuja una arquitectura barroca que se contrapone a una arquitectura funcional de deslumbrante eficacia: una máquina de matar, una máquina de aterrorizar, una máquina de "no morir", como The Terminator (1984-2015). A este respecto, Sandino Núñez (2010) ha establecido una tipología básica: el monstruo como mezcla y el monstruo como extravagancia. Se puede concluir que desde la mitología griega, el monstruo (theriantropía) es la expresión de la alteridad y por eso es símbolo de terror y de confrontación. La historia de las religiones ha propuesto explicaciones para estos delirios de transformación -por ejemplo, a través del chamanismo (Eliade, 1983) - y la ciencia moderna ha establecido puentes entre la antropología, la religión, la psicofarmacología y la botánica para entender los efectos de ciertas drogas asociadas a los trances rituales extáticos (Quirce y Maickel, 2009), elemento que se repite en el uso reiterado de las drogas como tema en la ciencia ficción futurista (Gray, 2000), cuya influencia vemos en películas como Enter the Void (2009).

Por lo tanto, la fascinación por aspectos y temas que rozan o entran de lleno en el terror tiene que ver, según el psicólogo Bettelheim (2006), con la catarsis y la proyección de una serie de conflictos que el adolescente o el adulto de las grandes ciudades plasma en fabulaciones del tipo Expediente $X$, relatos de psicópatas, etc., lo mismo que hace el niño al interiorizar los cuentos de hadas y referirlos a sus fobias y deseos más íntimos.

En todo caso, un monstruo es, a fin de cuentas, algo hecho con partes de otros diferentes: un híbrido. Es un ensamblaje de piezas, de lo heterogéneo. Así, los animales extraordinarios de las diversas mitologías se componen de acuerdo a un proceso similar al que Víctor Frankenstein utiliza para armar su criatura: cuerpo humano + cabeza de toro o de bisonte, o cabeza de león + alas o patas de águila, o todas las formas de serpiente/dinosaurio que parecen estar en la base de la representación del dragón, son ecuaciones similares en manos de "alguien + cerebro de otro", entes que ya son susceptibles de producirse según los avances de la ingeniería genética.

Aparte de sus expresiones como iconología literaria o artística que tanto han servido para explorar precisamente estos "bordes" o límites más o menos difusos entre lo animal, lo humano y la máquina (The Matrix, 1999; The Island of Dr. Moreau/La isla del Dr. Moreau, 1996), existen otras importantes implicaciones. Sloterdijk (2003) nos subraya, según venimos reiterando, que debemos aprender a convivir entre "personas, animales y máquinas" (Dennet, 1995); es decir, que el antropocentrismo clásico debe dar paso a una visión no ya solo ecologista y respetuosa con el medio 
ambiente (y por tanto con los animales), sino con las nuevas realidades que están por venir.

Así, el mundo de I, Robot (2004) prefigura los conflictos entre estos seres o artefactos, que surjan de la inteligencia artificial o de la biotecnología, y el mundo humano, tal como lo hemos venido conociendo. Se trata de un paso convergente en el camino de entender otras alteridades: las otras razas, los "extranjeros", tal vez los alienígenas (la serie Alien Nation, 1989-1990, abrió el camino hacia la consideración social del fenómeno).

El cerebro humano y la sociedad están asentados sobre códigos binarios, sobre bipolaridades o escalas de conceptos para "manejar la realidad": bello/feo, blanco/negro, grande/pequeño... Sin embargo, la cibercultura (Galindo, 2006), al poner en evidencia muchas de estas categorías y sus implicaciones (pensemos en la película The Incredible Shrinking Man/El increible hombre menguante, 1957), ha subvertido muchos estereotipos y también ha contribuido para elevar nuestro nivel de tolerancia. Por eso los monstruos, animales o psicópatas tienen a menudo alguna faceta que les da un "aire de familia" con la condición humana, en su sentido más elevado.

\section{Las máquinas “compañeras". La mujer biónica}

Frente a la visión casi tecnófoba que ve a las máquinas como "cacharros" o instrumentos que se oponen a la humanidad, que la desnaturalizan, en el imaginario posmoderno la máquina, el robot, es algo más que un auxiliar o ayudante, pasando a ser cada vez con más frecuencia un compañero, incluso un sustituto pleno cuando nuestro cuerpo se deteriora, como acontece en la película del mismo nombre.

Sin embargo, la desidealización también es evidente. En la saga fílmica Prometheus -que intenta ser la precuela de Alien-se alude a los creadores de los humanos como "ingenieros", es decir, fabricantes. Este choque entre lo emocional y lo puramente técnico es siempre un umbral que desborda el planteamiento de las posibilidades del cíborg o robot (Hassan, 1977). No se es humano por hacer en grado perfecto -como Supermán- las tareas propias de la humanidad; se es humano sobre todo por sentir, compartir, amar u odiar. Éste, como vemos en Blade Runner (1982), es el aprendizaje más complejo.

Tal como subraya Morin (1995), la literatura, en este caso la ficción, es la mejor "escuela de complejidad": cuando a los muñecos y los robots les asignamos rasgos antropocéntricos no solo los adaptamos a nuestra forma de percepción, sino que les individualizamos, les damos alma, mirada, expresión, atributos que los personalizan.

Esta tendencia ya no tiene marcha atrás; por ejemplo, en el episodio "Carne y piedra" de la serie Doctor Who, asistimos a un bosque recreado 
en una nave, que en realidad está formado por árboles-robots, que realizan todas las funciones de un bosque y tienen el mismo aspecto. Dicho de otro modo, los límites entre lo orgánico y lo biónico se solapan, y la propia emoción que dicho bosque despierta en el ser humano -antes de conocer su origen- es equivalente a la que despierta un paisaje natural. Por lo tanto, el problema es cada vez más la aceptación mental del "otro", aun cuando sea transfigurado de esta forma suplantadora, algo que el propio Ray Bradbury indagó en su obra Crónicas marcianas (1992). La familia redescubierta eran marcianos metamórficos, pero el protagonista llega, digamos, a un pacto cognoscitivo que realmente es un pacto emocional.

The Bionic Woman/La mujer biónica es una serie de televisión estadounidense que nace como un spin-off de la serie The Six Million Dollar Man/El hombre de los seis millones de dólares (El hombre nuclear en Hispanoamérica). En esta serie nació el personaje de Jaime Sommers, una tenista profesional que tras un accidente es convertida en la mujer biónica por Oscar Goldman y el Dr. Rudy Wells, quienes le implantan un oído mejorado ultrasensible, un brazo biónico y unas piernas que le permiten correr a gran velocidad (Martos García, 2010).

No olvidemos la conexión de toda esta imaginería con la perspectiva de género (Haraway, 1991): la nueva realidad social y cultural alumbrada por el llamado cíborg-feminismo que expresó en 1984 Donna Haraway en su "Manifiesto para cíborgs", constituye una superación del dualismo entre cultura popular/cultural dominante (Vainfas, 1996), y una reapropiación de este imaginario para empoderar a las mujeres, pues el cíborg clásico -por ejemplo en su versión de RoboCop- es un artefacto sin duda vinculado a la cultura patriarcal, militar e industrial. Por consiguiente, vemos que el personaje creado es la proyección de nuestros deseos individuales y colectivos; así, si una persona tiene un accidente que la desfigura, el avatar creado no es una simple restitución de sus facultades o funciones, es "otra cosa", algo a caballo entre lo humano y lo no humano (RoboCop, Avatar). Para muchos, los robots del futuro serán no solo simples máquinas auxiliares, sino auténtica mascotas donde se prolongarán los afectos de las personas reales. Todo ello no impide vislumbrar también las posibilidades (Clynes y Kline, 1960) en entornos hostiles como el espacio, las minas, etc., de cara a realizar determinadas funciones.

\section{Hacia un nuevo discurso sobre la muerte}

Una vez eliminado el pathos de la muerte, según hemos glosado, quedaría la dimensión ética y estética de la muerte que, como hemos visto, centran gran parte de las preocupaciones de la (pos)modernidad. 
Más allá del debate filosófico, las propuestas transhumanistas han traspasado los límites académicos. Por ejemplo, el libro infantil Death is Wrong (2013) contiene el claro mensaje de que se puede erradicar la muerte a través de la tecnología. Siendo ésta una cuestión controvertida, por un lado constituye un intento de desdramatizar, es decir, de superar una tradición macabra que viene desde las Danzas de la Muerte en Europa y que se prolonga a través de las diversas narrativas del género de terror.

En su contra, cabría alegar que la reducción del problema de la muerte al ámbito individual y biomédico es un intento peligroso de eludir otros aspectos de alcance social (Carenlos, 2009), que trasluce la persistencia de mitos como el de la fuente de la eterna juventud. Al rechazar la aceptación de la muerte -sin admitir siquiera posiciones tan inmanentistas como el budismo- se crea, por un lado, el espejismo de que controlar la inmortalidad está al alcance de la mano y se soslayan aspectos tan importantes como el sentido del dolor o la dimensión social de todo esto, especialmente en lo que se refiere a nuestras percepciones del futuro y la manera en que éstas afectarán a las propias decisiones individuales y colectivas.

En todo caso, hay diferentes visiones dentro de estas corrientes, desde los grupos que enfocan la muerte como una enfermedad tratable (De Grey, 2007) a otros que no se preocupan por la perspectiva metafísica de la inmortalidad, sino de mejorar la vida humana en términos de salud, y también los que consideran (Kurzweil, 2005) que la inmortalidad se puede propiciar a través del mundo digital, como en la película Transcendence (2014).

Entre utopías y distopías, entre la muerte como némesis, nihilismo o liberación cabe todo un mundo de matices, que son precisamente los que debe desarrollar una educación crítica y un pensamiento complejo (Morin, 1995) que no reduzcan la realidad a unos pocos paradigmas. Por suerte o por desgracia, no somos medusas ni lombrices y la tecnociencia-como bien avisan las ficciones aludidas- tiene una dimensión sombría que no debe olvidarse si queremos prevenir precisamente eso que se quiere evitar: las muertes gratuitas.

\section{Las representaciones posmodernas de la muerte como milenarismo y como catarsis colectiva}

La escritura posmoderna es como un gigantesco espejo -como la ficción que plantea Solaris, de Stanisław Lem-donde se reflejan las obsesiones, fobias y aspiraciones de la humanidad a una escala planetaria. Tal como venimos sosteniendo, en el fondo las personificaciones de superhéroes, alienígenas, máquinas, cíborgs, etc., tienen un denominador común: interrogar sobre la identidad y la alteridad. El "otro" es un conjunto híbrido de "personas" 
en un sentido etimológico; es decir, de "máscaras" que nos ayudan o nos amenazan, igual que los aliados y los agresores de los cuentos y mitos clásicos.

La principal contradicción se refiere a que en ambos casos, como se deduce de Castoriadis (1999), se renuncia a la autonomía por la heteronomía; es decir, externalizamos las fuerzas o principios del bien y del mal como si fueran ajenos a nosotros, como si se dependiera de estas fuerzas externas para resolver o empeorar los problemas. De hecho, en estos relatos de superhéroes o de asesinos/monstruos el común de las personas, la "plebe", es solo un personaje coral, una víctima pasiva, de tal modo que el protagonismo corre siempre de parte del monstruo o victimario, o de quien trata de "salvarnos", el "líder" que emerge siempre en estas catástrofes, a imagen y semejanza del culto capitalista al individuo emprendedor.

Los mitos de redención están, pues, en la base y eso da idea del tono kitsch de nuestra cultural, de la calculada ambigüedad, pues no se busca la mayor implicación de la colectividad o la subjetividad crítica, como dice Castoriadis (1999), sino una identificación morbosa. De hecho, en muchos relatos de superhéroes la gente no comprende o incluso rechaza a su salvador, siendo este otro ejemplo de menosprecio a la inteligencia colectiva.

Todo ello ayudado por la tendencia irrefrenable de nuestro cerebro al pensamiento binario. Sin embargo, la posmodernidad fomenta figuraciones mixtas y relativismos (Bauman, 2005) que entran en circulación con los otros artefactos culturales (Martos y Martos, 2014), especialmente con la cultura hegemónica, la prestigiada por los círculos "cultos". Por ejemplo, todo el mundo variopinto de los superhéroes es una reinvención barroquizante e híbrida del politeísmo clásico o del santoral cristiano, que reproduce una forma de religiosidad popular aún latente en nuestra sociedad, pese a la tecnolatría.

Se produce así un flujo y reflujo entre ambas: culturas hegemónicas y culturas marginales. Lo cierto es que el éxito, el mercado, la presencia apabullante de la industria del entretenimiento hacen que la "alta cultura" se vea obligada a modificar sus posiciones de partida, que sea permeable a ciertos fenómenos porque, a su vez, los ensayistas, críticos o narradores, digamos, más formados también prestan oídos a esta nueva sensibilidad:

La cultura popular, según Ginzburg, se define, antes que todo, por su oposición a la cultura letrada u oficial de las clases dominantes, lo que confirma la preocupación del autor por recuperar los conflictos de las clases en una dimensión socio cultural globalizante. Pero, la cultura popular se define, también, por las relaciones que mantiene con la cultura dominante, filtrada por las clases subalternas de acuerdo con sus propios valores y condiciones de vida. Es a propósito de esta dinámica entre 
los niveles culturales, popular y erudito, que la cultura letrada filtra a su modo los elementos de la cultura popular, y es que Carlo Ginzburg, propone el concepto de circularidad cultural. (Vainfas, 1996: 226)

Por lo tanto, el mecanismo de la cultura popular es el contagio y sus agentes son los aficionados; no solo los consumidores sino también, gracias a la sociedad de la información y de herramientas como la Web 2.0, los productores, llegándose así al concepto de "prosumidores". Hay críticos, como María Nikolajeva (1998), que ven en las tendencias de la literatura juvenil contemporánea una huella asimilable a la escritura posmoderna, en el sentido de eclecticismo, desintegración de las convenciones y estructuras narrativas tradicionales, intertextualidad/interdiscursividad, etc. The Lord of the Rings/El Señor de los Anillos, por ejemplo, impuso todo un sinfín de sagas que, sin duda, eran imitaciones y nuevas versiones/adaptaciones. En este sentido, puede considerarse un equivalente cinematográfico de lo que Lubomír Doležel (1998) ha denominado como la reescritura posmoderna en su variedad de desplazamiento.

Para Doležel, la reescritura posmoderna recupera el pasado a la vez que reinterpreta sus formas. La reescritura no solo se enfrenta al mundo ficcional canónico con los postulados estéticos e ideológicos contemporáneos, sino que también proporciona al lector un espacio conocido dentro de los paisajes extraños de la experimentación radical posmoderna. En ese periodo, directores como Tarantino o los hermanos Coen saltaron a la popularidad con un cine profundamente autorreferencial e intertextual, donde el reciclaje de fórmulas y géneros, la violencia y la sexualidad se combinaban en elaboradas narrativas de gran riqueza formal y temática. El propio término artsploitation es un reflejo de la ruptura posmodernista entre la alta y la baja cultura que ha sido analizado por Jameson (1995: 23):

[...] los artistas del período "posmoderno" se han fascinado precisamente por el nuevo mundo de objetos, no meramente por Las Vegas sino por las películas de Hollywood de clase B, por la así llamada paraliteratura con sus categorías de libro de aeropuerto, de novela gótica y romántica, la biografía popular, policiales y de misterio, y la ciencia ficción o la novela fantástica (de una forma tal que las antiguas categorías genéricas desacreditadas por el modernismo ahora experimentan una reaparición inesperada).

La obsolescencia de las formas estilísticas, la "canibalización" de los estilos del pasado y la hibridación son, según Carbajosa (2011), algunos de los rasgos del posmodernismo, en muchos casos a través de la búsqueda 
de la atemporalidad del relato o la nostalgia. Lo cierto es que la fragmentación, multiplicación o hibridación de materiales fabulísticos es una constante en la estética posmoderna y, a veces, lleva a convertir la lectura en un galimatías. La posmodernidad implica desmantelamiento de los viejos códigos, su desmitificación y, al mismo tiempo, el reciclaje o recombinación de las convenciones artísticas o literarias en formas que resultan híbridas.

Tal como aparece en El Rastro, de Ramón Gómez de la Serna, en su ámbito urbano (Cooke, 1988), las formas artísticas se presentan como un almacén heterogéneo y discontinuo de enseres y objetos donde el artista realiza su "expurgo". El material resultante hace gala del sincretismo y la contaminación de relaciones transtextuales de todo tipo. Otro exponente de esta fragmentación y de su reordenación a través del reciclaje y la hibridación es el discurso de los media, la popularidad de los magazines, pastiches y toda suerte de imitaciones.

Por otro lado, la interdiscursividad de las propuestas hace patente la permeabilidad entre cine, literatura, cómic, televisión, etc., lo cual retoma de algún modo el origen de la fabulación que estaba en la palabra, pero que ya en sus comienzos se acompañaba de danza, mímica, sonido... como puede apreciarse por los testimonios del cuentacuentos, del brujo, del chamán al contar los mitos de la tribu; además, estos relatos también pretendían explicar la identidad de la comunidad y cómo actuar, de ahí el carácter ritual y ejemplar (Eliade, 1983) que tenían estas narraciones ancestrales, cercano al sentimiento de pertenencia que emana de estos héroes y monstruos, profundamente tribales.

De hecho, pronto la imagen acompañó a la palabra; por ejemplo, las pinturas rupestres son a menudo narraciones de mitos de la tribu, como lo son en gran medida las vidrieras de las catedrales medievales. En época moderna, los libros de imágenes han sido reforzados con los nuevos discursos y canales del cómic, el cine, la televisión, los videojuegos... Por eso, hoy en día las ficciones fantásticas pasan de un "troquel" a otro: pueden nacer primero como cómic y de ahí pasar al cine o al libro, o al revés, de un cuento literario se toma el guion para armar una película, como sucedió con Do Androids Dream of Electric Sheep?/¿Sueñan los androides con ovejas eléctricas?, de Philip K. Dick, para el famoso Blade Runner.

En todo caso, los monstruos, máquinas y cíborgs nacidos al amparo de la imaginación popular desempeñan una función catártica. A través de ellos, el ser humano proyecta sus temores y sus preocupaciones, escenificando así el mal, el sufrimiento, el miedo a lo extraño, a lo oculto, a lo siniestro, a lo transgresor, externalizando estas fuerzas en un intento de dar respuestas a los aspectos más enigmáticos y estremecedores que nos rodean. 
El ciberpunk es más pesimista (Person, 1998), levanta más bien distopías, universos de pesadilla -anclados en la realidad presente- donde fenómenos como la hegemonía de la información, la contaminación de la naturaleza, las drogas, las metrópolis inmensas... todo confluye para trazar un cuadro negativo, incluso apocalíptico, del porvenir (Encabo et al., 2016), pero donde también se alumbra, por vía del imaginario, una serie de representaciones milenaristas como en las sagas de The Terminator, donde la máquina vuelve a convertirse en aliada del hombre para poner en pie la utopía (Martos García, 2010).

De todas estas historias fantásticas podríamos repetir esas bellas palabras de G. Gliemmo a propósito de Juan Carlos Onetti: "El núcleo de creación de la saga es una ficción preñada, la narración que se guarda en el interior de otra ficción" (Gliemmo, 1994). En sintonía con la narrativa posmoderna, pero también con la propia andadura del ser humano, las sagas utilizan el reciclaje y la hibridación, crean y desmantelan mundos, colocan y descolocan, y, en definitiva, se van armando pacientemente desde un principio u origen, pero al final acaban "donde pueden".

Ojalá esta infinidad de posibilidades aliente muchas pasiones por la ficción y las artes, que serán a la postre pasiones por una visión más humanista de la vida... o poshumanistas, no en vano Sloterdijk (2003) llama nuevas poligamias ontológicas a las relaciones que el poshumanismo propone entre hombre/mujer y máquinas, a todos los niveles, que sin duda influirán de forma decisiva en el desarrollo de la humanidad desde hechos que ya hoy son factibles - por ejemplo, que los vehículos sean conducidos por máquinas que sustituyen a las personas- hasta umbrales difíciles de imaginar todavía. Muchas otras dimensiones se abren, como evidencian películas similares a The Matrix (1999-2003), de los hermanos Wachowski o Videodrome (1983) de David Cronenberg.

Por lo demás, ya hemos visto (Pintos, 2006) que la muerte, más allá de un hecho biológico, es una construcción social muy elaborada donde, por ejemplo, los "grupos de duelo" (ibidem:589) comparten sus experiencias; es decir, construyen un sentido autorreferente que es relevante para esa comunidad y que ninguna doctrina, norma o verdad científica puede construir por ellos. De hecho, el paso de la idea de la "buena muerte" (Ars Moriendi), inspirada en principios morales o religiosos, a la "muerte digna" es un signo evidente de los cambios sociales, al igual que los tanatorios respecto a los rituales funerarios tradicionales.

Es un espejismo suponer que la ciencia sustituirá a la religiosidad tradicional; al contrario, algunos antropólogos (Martorell Campos, 2012) subrayan que el transhumanismo es en esencia una utopía de la sociedad posmoderna, 
que ha pretendido emanciparse del cuerpo (Le Breton, 1996; Hayles, 1999). Muchos de estos imaginarios serían, pues, tecnotopías que supondrían un giro postmoderno de las utopías clásicas de naturaleza "pospolítica, egocrática, consuelo del narcisista posmoderno, abducido únicamente (y en dicha exclusividad yace la tara) por angustias personales, entre ellas, de manera preferente, la caducidad del cuerpo" (Martorell, 2012: 495).

\section{Conclusiones}

Por lo tanto, no cabe una interpretación común y universalizada de la muerte, ni siquiera por la imposición de los valores del mercado, de la tecnociencia y del capitalismo avanzado. La muerte precisamente es el límite o umbral de la vida y no sabemos qué nos aguarda o si nos aguarda algo.

Hasta el punto de que los ultramundos representados en los arquetipos clásicos, desde el Cielo al Infierno, no dejan de ser especulaciones que no deben hacernos renunciar a imaginar y construir nuevas formas de vida "aquí", máxime cuando vivimos en el seno de sociedades atravesadas por crisis, urgencias y convulsiones sociales.

Como un Jano (pos)moderno, las personas del siglo XXI no deben evitar mirar hacia atrás ni tampoco mirar hacia adelante, sin olvidar mirar hacia abajo o hacia los lados; es decir, a toda la topografía social e imaginaria que confiere nuestra ubicación en el mundo y que se desliza, por ejemplo, entre una visión del cuerpo tal como se percibía en el humanismo clásico y el cuerpo poshumano, en apariencia -solo en apariencia- superadora del sinsentido de la muerte.

Bajo estas nuevas sensibilidades, es normal percibir que "máquina, hombre y naturaleza" forman un todo (Sloterdijk, 2003) y que figuras como el cíborg, al relativizar el concepto de cuerpo o la diferencia entre lo orgánico y lo tecnológico, expresen una nueva cosmovisión donde lo tecnológico y las antiguas preocupaciones humanistas se (re)concilian, tal como se expresa en Avatar en las preguntas finales que tanto los humanos como el robot dirigen a los seres superiores o "ingenieros" responsables de la creación humana.

De este modo, llegamos a la visión más posmoderna: la elaboración de la cultura como fruto de la hibridación y el reciclaje de los distintos "materiales" y, por lo tanto, la superación de las viejas antinomias entre cuerpo y alma, espíritu y materia, sujeto y objeto, libertad y determinismo. Las ficciones glosadas plantean un mundo en el que los nuevos conceptos mentales y tecnológicos están tan arraigados que no es posible trazar una división clara entre el yo y el mundo o entre lo que agrega (o simula) la cultura y lo que es naturaleza.

Al final, la hibridación es el sello de la identidad posmoderna y por eso los cíborgs de Blade Runner se humanizan a medida que cobran conciencia 
de su propia muerte, no como una simple previsión de datos, sino en el sentido más humano de la angustia o el temor. $\mathrm{O}$, más ingenuamente, como los robots de Star Wars (1977) se colocan al lado de la utopía positiva como esas máquinas radicales que postulan los activistas de la sociedad de la información, capaces de hacer frente al "tecnoimperio".

El ciberpunk, más pesimista, levanta más bien distopías, universos de pesadilla anclados en la realidad presente, donde fenómenos como la hegemonía de la información, la contaminación de la naturaleza, las drogas, las metrópolis inmensas... todo confluye en trazar un cuadro negativo, si no apocalíptico, del porvenir. Pero donde también se alumbra, por vía del imaginario, una serie de representaciones milenaristas, pues, como en las sagas de The Terminator, la máquina vuelve a convertirse en aliada del hombre para poner en pie la utopía (Martos García, 2010).

Alianzas que encubren realmente otro pilar del imaginario: el destino de todos los seres está comprometido, todos se salvarán o se perderán juntos. Esta idea milenarista arranca de una visión que tiene su origen en los mitos mesiánicos arcaicos. El todo y la parte son solidarios, la degradación de un solo hombre, de una sola ciudad, son las señales de la conflagración universal.

El nexo entre el milenarismo y la superación de la muerte es precisamente la carga simbólica que la herencia cultural ha venido depositado en estas nociones-eje: el milenarismo es el fin de un ciclo y el alumbramiento de un nuevo mundo mediante una "promesa", "buena nueva" o "mundo alternativo", según queramos expresarlo en términos más espiritualistas o tecnológicos. La muerte, individual o colectiva, literal o metafórica, es el signo del tiempo caduco, que es abolido por la "promesa". Las mitologías antiguas hablaban de "regeneración" o de poderes como los del chamán, que podía externalizar su alma; los imaginarios modernos visualizan la muerte y su reverso (por ejemplo, los poderes extraordinarios de los superhéroes) en forma de gadgets, dispositivos o tecnologías, pero ambos se sustentan en la "esperanza" como una forma de conocimiento o predicción de los cambios por venir (Asimov, 1986). En esta línea, hay propuestas artísticas de gran interés como las del bioarte (Stelarc, 2000), planeando escenarios constructivos y destructivos de formas de vida, y combinando aportaciones de la nanotecnología, la inteligencia artificial general y la ciencia cognitiva. La muerte como predicción (al igual que las catástrofes) se convierte en una variable, no en algo inexorable que desencadena un sentimiento trágico de la vida (De Unamuno, 1983 [1912]).

Por eso no es de extrañar que en el ciberpunk las distopías subyacentes de muchos libros, sagas, mangas o películas partan de una actitud tecnófoba, 
de una visión negativa de la tecnología. Subrayan que, si bien aporta nuevas herramientas, no deja de crear otros conflictos más graves: antiuniversos, como los retratados en The Matrix (1999) o The Terminator (1984-2015); mundos infectados por la extensión de virus, como en diversas distopías; totalitarismos como en $V$ for Vendetta (2005); o bien problemas originados por los robots que crean los humanos, Surrogates (2009), que llegan a producir resultados apocalípticos o situaciones de auténtico peligro. La muerte y sus figuraciones son, en resumen, la parábola y el compendio de todos estos conflictos.

Revisado por José Morales

\section{Referencias bibliográficas}

Asimov, Isaac (1986), Sobre la ciencia ficción. Barcelona: Edhasa.

Asimov, Isaac (1950), I, Robot. New York: Bantam Dell.

Bauman, Zygmunt (2005), Modernidad líquida. México: Fondo de Cultura Económica. Begoña, José (1980), "Evaluación y contraste dentro de una de las constantes de Ramón Gómez de la Serna”, Actas del Sexto Congreso Internacional de Hispanistas. Toronto: University of Toronto, 94-98.

Bettelheim, Bruno (2006), Psicoanálisis de los cuentos de hadas. Barcelona: Editorial Crítica.

Bostrom, Nick (2011), "Una historia del pensamiento transhumanista", Argumentos de razón técnica: Revista española de ciencia, tecnología y sociedad, y filosofía de la tecnología, 14, 157-191.

Bradbury, Ray (1992), Crónicas marcianas. Barcelona: Ediciones Minotauro.

Braet, Antoine C. (1992), "Ethos, Pathos and Logos in Aristotle's Rhetoric: A Re-examination”, Argumentation, 6(3), 307-320.

Carbajosa Palmero, Natalia (2011), "De la vanguardia a la visión: imágenes y modos de representación en la poesía de HD”, Signa: Revista de la Asociación Española de Semiótica, 20, 419-445.

Carenlos Resende, Daiane; Cava Guimarães, Josiane (2009), “'Da morte a vida’: um estudo sobre o imaginário da morte”, I Seminario Nacional Sociología \& Política UFPR. Consultado el 06.11.2016, en http://www.humanas.ufpr.br/site/evento/ SociologiaPolitica/GTs-ONLINE/GT8\%20online/EixoIV/da-morte-a-vidaDaianeResende.pdf.

Castoriadis, Cornelius (1999), L'institution imaginaire de la société. Paris: Editions du Seuil.

Clynes, Manfred; Kline, Nathan S. (1960), "Cyborgs and Space", Astronautics (Sept), 26(27), 74-75. 
Cooke, Philip (1988), "Modernity, postmodernity and the city", Theory, Culture \& Society, 5(2-3), 487-489.

Cruz, Rodrigo Díaz (2009), “Al acecho de la perfección. Transhumanismo, el cuerpo oscuro y la vía religiosa de la tecnociencia”, Antropología. Boletín Oficial del INAH, $87,29-45$.

De Grey, Aubrey (2007), "Life Span Extension Research and Public Debate: Societal Considerations", Studies in Ethics, Law, and Technology, 1(1), 1-10.

De Unamuno, Miguel (1983), Del sentimiento trágico de la vida. La agonía del cristianismo, vol. 113. Madrid: Akal [ed. orig.: 1912].

Dennet, Daniel (1995), La conciencia explicada. Barcelona: Paidós.

Deleuze, Gilles; Guattari, Félix (1972), Capitalisme et schizophrénie 1. L'Anti-Edipe. Paris: Minuit.

Doležel, Lubomír (1998), Heterocosmica: Fiction and Possible Worlds. Baltimore, Maryland: Johns Hopkins University Press.

Echarte Alonso, Luis Enrique (2012), "Neurocosmética, transhumanismo y materialismo eliminativo: hacia nuevas formas de eugenesia", Cuadernos de Bioética, 23(77), 37-51.

Eliade, Mircea (1983), Imágenes y símbolos. Madrid: Taurus.

Encabo, Eduardo; Urraco, Mariano; Martos, Aitana (2016), Sagas, distopias y transmedia: ensayos sobre ficción fantástica. León: Universidad de León.

Fernández Blanco, Manuel (2004), "La adolescencia hoy: adultos prematuros, niños eternos”, Cuadernos de Atención Primaria, 11(2), 61-65.

Fernández Castrillo, Carolina (2008), "Máquinas \& almas: arte digital y nuevos medios”, Lápiz: Revista Internacional del Arte, 246, 68-75.

Fukuyama, Francis (2002), Our Posthuman Future. Consequences of the Biotechnology Revolution. London: Profile Book.

Galindo, Jesús (2006), Cibercultura: un mundo emergente y una nueva mirada. México: Conaculta e Instituto Mexiquense de Cultura.

García Díaz, Silvia; Gutiérrez Ramírez, Carmen; Hervás Ballesteros, Raquel (2004), "Estudio de la evolución de vida artificial: ALiS (Artificial Life Simulation)". Trabajo de la asignatura Sistemas Informáticos, Facultad de Informática, Universidad Complutense de Madrid, España. Consultado el 02.08.2016, en http://eprints.ucm. es/9286/.

Gliemmo, Graciela (1994), "Juan Carlos Onetti: una poética del fragmento Ensayos críticos y periodísticos sobre literatura", Primeras Jornadas Rioplatenses de Literatura, 27 al 29 de abril de 1994. Montevideo: Facultad de Humanidades y Ciencias de la Educación. Consultado el 05.01.2016, en http://www.sololiteratura.com/one/ onettimiscprimeras.htm.

Gray, Chris Hables (2000), Cyborg Citizen: Politics in the Posthuman Age. New York: Routledge.

Haraway, Donna (1991), Simians, Cyborgs and Women. London: Free Association Books. 
Hardt, Michael; Negri, Antonio (2000), Empire. Cambridge, Massachussetts: Harvard University Press.

Hassan, Ihab (1977), "Prometheus as Performer: Toward a Postmodern Culture?", in Michel Benamou, Charles Caramello (comps.), Performance in Postmodern Culture. Madison, Wisconsin: Coda Press.

Hayles, N. Katherine (1999), How We Became Postbuman: Virtual Bodies in Cybernetics, Literature, and Informatics. Chicago: University Of Chicago Press.

Jameson, Fredric (1995), El posmodernismo o la lógica cultural del capitalismo avanzado. Barcelona: Paidós.

Kurzweil, Ray (2005), The Singularity is Near: When Humans Transcend Biology. New York: Penguin.

Latour, Bruno (2011), “Love Your Monsters”, Breakthrough Journal, 2(11), 21-28.

Le Breton, David (1996), "Lo imaginario del cuerpo en la tecnociencia”, Salud Mental, 19(3), 7-13.

Lee Stan; Kirby, Jack (1963), The Avengers. Marvel (Comics).

Lévi-Strauss, Claude (1987), Antropología estructural: mito, sociedad, bumanidade. Buenos Aires: Siglo XXI.

Lyon, David (1997), Postmodernidad. Madrid: Alianza.

Martorell Campos, Francisco (2012), “'Al infierno los cuerpos’: el transhumanismo y el giro postmoderno de la utopía”, Thémata. Revista de Filosofía, 46, 489-496.

Martos García, Alberto Eloy (2010), "Imaginarios tecnocientíficos y humanismo: repercusiones para la educación”, Educación y Futuro Digital, 23, 489-496.

Martos Núñez, Eloy; Martos García, Alberto Eloy (2013), "Imaginarios del devoramiento en la cultura del agua: dragones, tragantía, tragaldabas y otros espantos”, Indivisa: Boletín de Estudios e Investigación, 13, 122-143.

Martos Núñez, Eloy; Martos García, Alberto Eloy (2014), “Artefactos culturales y alfabetización en la era digital: discusiones conceptuales y praxis didáctica”, Teoría de la Educación, 26(1), 119-135.

Moore, Alan; David Lloyd (2006), V for Vendetta. Jakarta: Gramedia Pustaka Utama.

Morin, Edgar (1995), Introducción al pensamiento complejo. Barcelona: Gedisa.

Nikolajeva, Maria (1998), "Exit Children's Literature?", The Lion and the Unicorn, 22(2), 221-236.

Núñez, Sandino (2010), Probibido pensar. Montevideo: Hum.

Person, Lawrence (1998), “Notes Toward a Postcyberpunk Manifesto”, Nova Express, 16. Consultado el 27.10.2015, en http://slashdot.org/story/99/10/08/2123255/ notes-toward-apostcyberpunk-manifesto.

Pintos, José Luis (2006), “Tanatorios vs. velorios: las transformaciones de los imaginarios sociales de la muerte en el último decenio", Semata: Ciencias Sociais e Humanidades, 17, 563-598.

Propp, Vladimir (1985), Morfología del cuento. Madrid: Akal [ed. orig.: 1928]. 
Pulido Tirado, Genara (2012), "Vida artificial y literatura: mito, leyendas y ciencia en el Frankestein de Mary Shelley”, Tonos Digital, 23(1), 1-28.

Quirce Balma, Carlos; Maickel, Roger (2009), "Los alucinógenos y los teoremas de 'Gating' en la acción psicofarmacológica alucinatoria y en la esquizofrenia”, Revista Costarricense de Psicología, 28(41-42), 85-99.

Raulerson, Joshua (2013), Singularities: Technoculture, Transhumanism, and Science Fiction in the Twenty-First Century, 45. Oxford: Oxford University Press.

Rowen, Norma (1992), “The Making of Frankenstein's Monster: Post-Golem, Pre-Robot”, in Nicholas Ruddick (comp.), State of the Fantastic: Studies in the Theory and Practice of Fantastic Literature and Film. Greenwood: Pub. Group, 169-177.

Shelley, Mary Wollstonecraft (2009), Frankenstein, or The Modern Prometheus. Engage Books, AD Classic [ed. orig.: 1818].

Shirow, Masamune (1996), Ghost in the Shell. New York: Kodansha America LLC [ed. orig.: 1989].

Sloterdijk, Peter (2003), Temblores de aire, en las fuentes del terror. Valencia: Pre-Textos.

Stelarc (2000), "Interview Stelarc", in Arjen Mulder; Maaike Post (comps.), Book for the Electronic Arts, 2, 24-32.

Stolyarov, Gennady (2013), Death is Wrong. New York: Rational Argumentator Press. Toffler Alvin (1970), El shock del futuro. Barcelona: Plaza y Janés.

Tolkien, John Ronald Reuel (1994), "Sobre el cuento de hadas", Árbol y boja. Barcelona: Minotauro, 43-44.

Vainfas, Ronaldo (1996), "De la historia de las mentalidades a la historia de la cultura", Anuario Colombiano de la Historia Social y de la Cultura, 23, 219-233.

Vronsky, Peter (2004), Serial Killers: The Method and Madness of Monsters. New York: Penguin Books.

\section{Lista de películas}

Arnold, Jack (1957), The Incredible Shrinking Man. Universal International Pictures.

Cameron, James (1984-2015), The Terminator. Hemdale Film, Cinema '84, Euro Film Funding y Pacific Western.

Cronenberg, David (1983), Videodrome. Canadian Film Development Corporation (CFDC).

Frankenheimer, John (1996), The Island of Dr. Moreau. New Line Cinema.

Kubrick, Stanley (1968), 2001: A Space Odyssey. Metro-Goldwyn-Meyer.

Lucas, George (1977), Star Wars. Lucasfilm y Twentieth Century Fox.

McTeigue, James (2005), V for Vendetta. Vertigo Visual Studios.

Mostow, Jonathan (2009), Surrogates. Film France.

Noé, Gaspar (2009), Enter the Void. Buena Vista.

Pfister, Wally (2014), Transcendence. Alcon Entertainment. 
Proyas, Alex (2004), I, Robot. Twentieth Century Fox.

Scott, Ridley (1982), Blade Runner. The Ladd Company, Shaw Brothers y Warner Bros.

Scott, Ridley (2012), Prometheus. Scott Free Brandywine Productions.

Verhoeven, Paul (1987), RoboCop. Orion Pictures.

Wachowski, Andy; Wachowski, Larry (1999-2003), The Matrix. Warner Brothers Pictures.

Whedom, Joss (2012-2018), The Avengers. Marvel Studios.

Recibido: 25.12.2016

Aceptación comunicada: 23.01.2018

Aitana Martos García

Departamento de Educación, Universidad de Almería

Ctra. Sacramento s/n, La Cañada de San Urbano, 04120 Almería, España

Contacto: amartosg@ual.es

\section{Alberto E. Martos García}

Departamento de Didáctica de las Ciencias Sociales, Universidad de Extremadura

Avenida de Elvas, s/n, 06071 Badajoz, España

Contacto: albertomg@unex.es

\section{Imaginaries and Fictions of Death in Postmodernity}

This essay analyses the exchange and lability between the fictional representations of death in the context of a postmodern culture, where an artificial intelligence and other cultural and scientific currents have remodelled basic notions such as ideas of spirit or death. Post-humanism assumes a new horizon by emphasising the new relationships between people, animals and machines and is preceded by the visions of trans-humanism, which implies an inversion of traditional world views about the body and death. The hypothesis of the present work is the techno-scientific imaginaries, through futurist fiction in particular, have remodelled the idea of death that goes from being a fatum to an anomaly

\section{Imaginaires et fictions de la mort dans la postmodernité}

Cet essai se penche sur l'échange et la labilité entre les représentations fictionnelles de la mort dans le contexte d'une culture postmoderne, où l'intelligence artificielle et d'autres courants culturels et scientifiques ont remodelé des notions de base telles que les idées de l'âme ou de la mort. Le post-humanisme crée un nouvel horizon en mettant en relief les nouveaux rapports entre les êtres humains, animaux et machines, et est précédé par les points de vue du transhumanisme, qui implique un renversement des cosmovisions traditionnelles à propos du corps et de la mort. L'hypothèse du présent travail est que les imaginaires technoscientifiques, particulièrement à travers des fictions futuristes, 
or mechanism that can be corrected with science. We can conclude that many of the utopias recreated in the imaginaries are techno-utopias typical of post-modernity, and in that aspect, these post-modern representations of death continue to have meaning as an expression of a millenarianism and a collective catharsis that reconcile the rational and irrational dimension.

Keywords: artificial intelligence; imaginary death; posthumanism; postmodernity. ont remodelé l'idée de la mort, qui cesse d'être un fatum pour devenir une anomalie ou un mécanisme qui peut être corrigé par la science. Il nous est donné de conclure que nombre des utopies recréées dans les imaginaires sont des technotopies propres à la postmodernité et que, de la sorte, de telles représentations postmodernes de la mort comme expression d'un millénarisme et d'une catharsis collective qui réconcilient la dimension rationnelle et la dimension irrationnelle humaine, prennent tout leur sens.

Mots-clés: intelligence artificielle; imaginaire de la mort; post-humanisme; postmodernité. 
